\title{
Engraved in Copper: The Art of Mapping Minnesota
}

This eXhibit Highlighted uniQue engraved copper plates that were used to print topographic maps of Minnesota in the early 1900s, as well as surveying and mapmaking techniques, and government documents related to the process. The plates are part of the evolution of government mapping and cartography and the history of the United States Geological Survey (USGS), from early mapping efforts to modern Geographic Information Systems (Figure 1).

The idea for this exhibit formed in early 2015, shortly after the University of Minnesota Libraries received its first shipment of copper plates from the USGS. Once the exhibit proposal had been accepted, we worked with staff

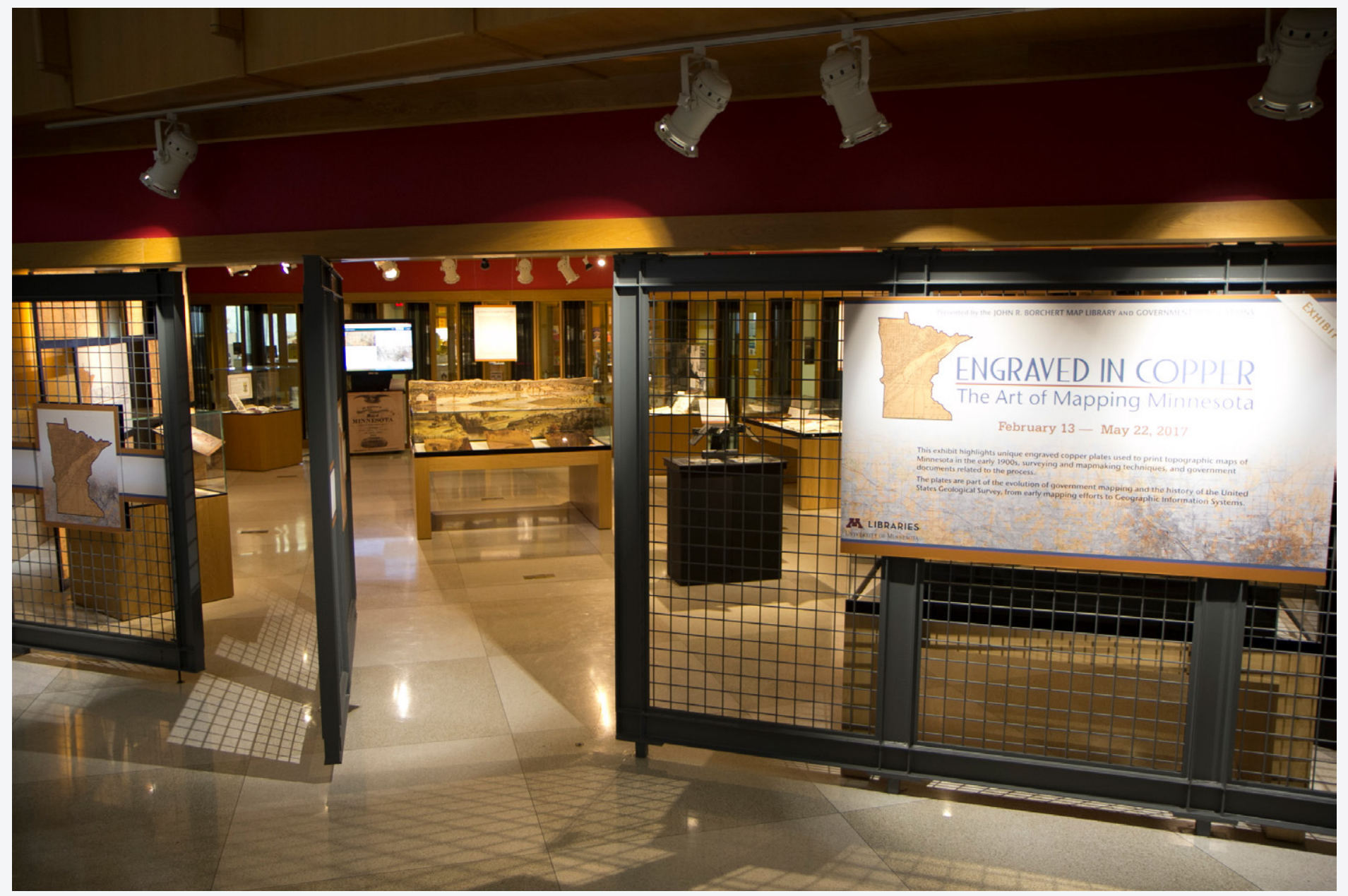

Figure 1. The exhibit in the Elmer L. Andersen Library at the University of Minnesota. 


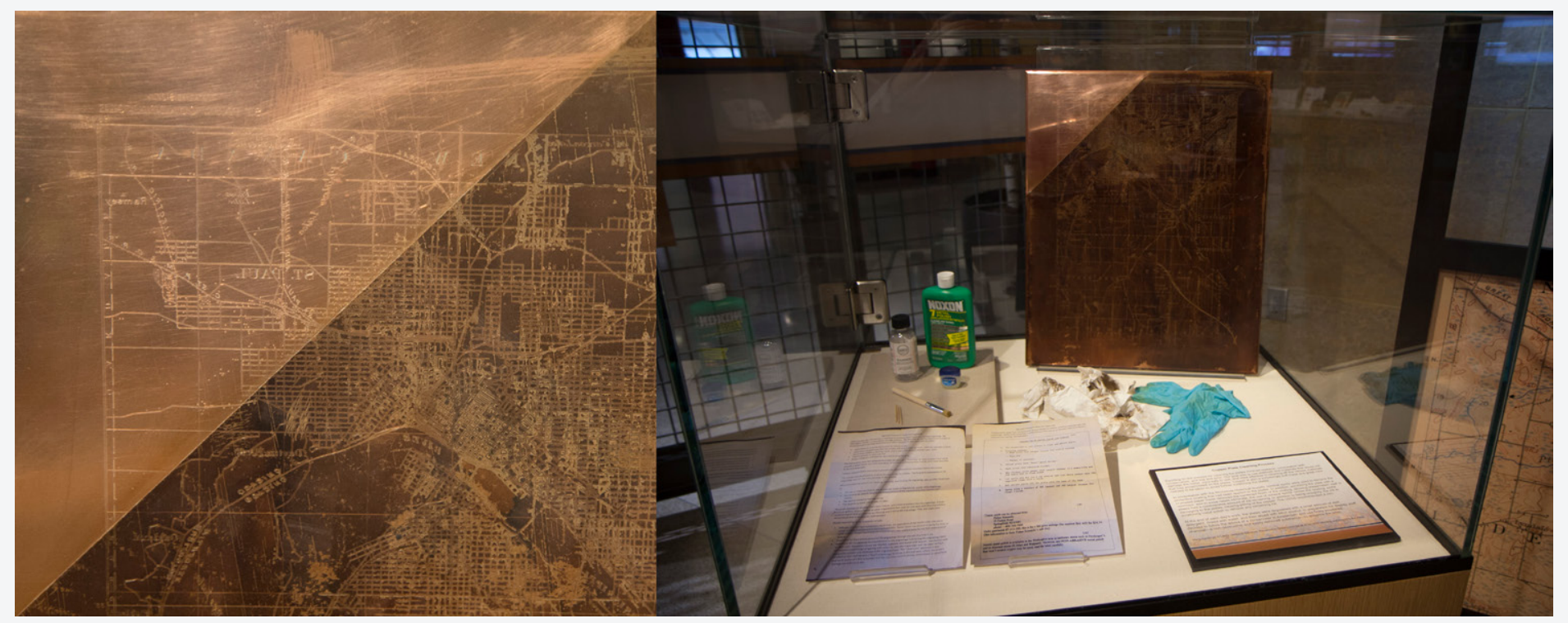

Figure 2. Left: detail of a copper plate showing before and after cleaning. Right: display case highlighting the cleaning process.

from the Preservation Department in order to clean the plates and prepare them for display (Figure 2).

Preparing the exhibit also involved securing the use of several artifacts and objects for display. These included engraving tools from the USGS office in Rolla, Missouri, as well as examples of numerous types of surveying equipment from the local Historical Surveyors group, such as a transit, a heliotrope, an alidade, and a surveyor's chain, just to name a few.

The systematic topographic mapping of the United States commenced after John Wesley Powell, Director of the USGS, convinced Congress to begin to fund the effort in the 1880s. By 1954, the USGS had mapped nearly 1 million square miles (approximately 33\%) of the land in the continental United States (Evans 2009, 144). During this period, maps printed using copper plates were produced by the Map Division of the USGS. In addition to elevation and water features, they generally indicated cultural features such as roads, streets, cities, towns, buildings, cemeteries, and mines. Three copper plates were needed to produce each printed map. Each plate was used to print a single color-black ink for text and to indicate human or cultural landscape features, brown ink for topographic contour lines indicating elevation, and blue ink for water and wetland features.

Between the 1930s and the 1950s, the USGS transitioned away from the copper plate engraving process due to the rise of the photolithographic printing process, which was faster and less expensive (Evans 2009, 97). The last maps produced by the USGS using copper plates were printed in the early 1950s. In 2014, the USGS announced the offer of more than 1,200 sets of copper plates as donations to federal, state, and local government agencies and departments, as well as qualifying non-profit organizations and educational institutions (USGS 2015). The John R. Borchert Map Library at the University of Minnesota received 12 sets, including some of the sets featured in the exhibit (Figure 3).

The copper plates are the main feature of the exhibit but, to give additional context to the plates, it also included an

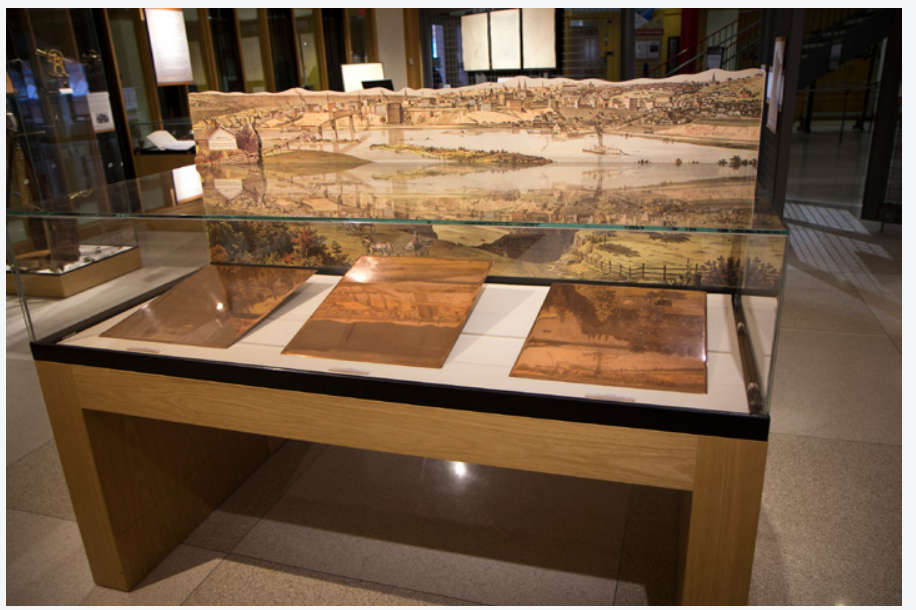

Figure 3. Three of the copper plates featured in the exhibit. 


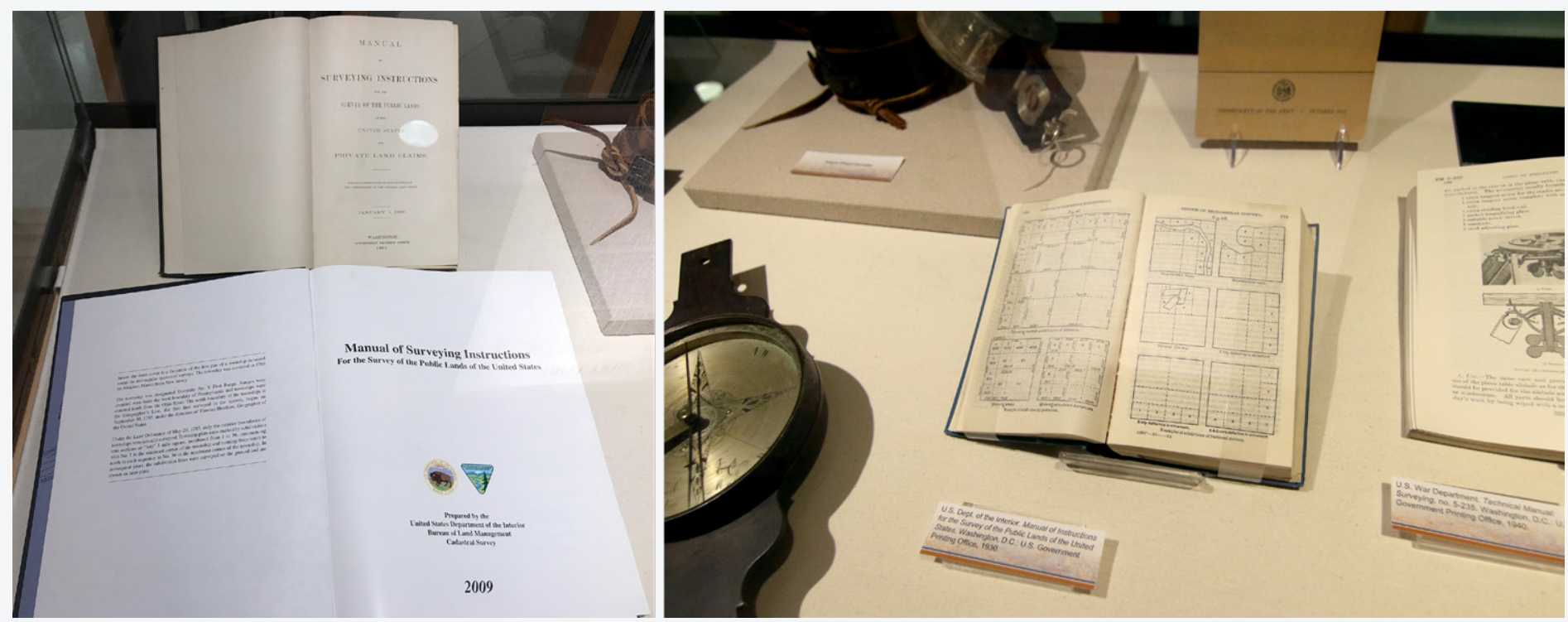

Figure 4. Interior of a display case focused on surveying.

overview of mapmaking, beginning with the surveying process.

The art of surveying dates back to ancient times, beginning with the construction of the pyramids nearly 7000 years ago by the Egyptians (US Dept. of the Interior 1988, 1). In the United States, surveying began after the Revolutionary War and the subsequent Louisiana Purchase in 1803 (US Dept. of the Interior 1988, 3). The American government recognized the need to map the vast amount of unsettled land west of Pennsylvania that had come into the public domain, and thus the public land surveys began. Various editions of the Manual of Surveying Instructions, published by the Department of Interior and spanning from the early 1900s to early 2000s, were displayed to demonstrate the continuing importance and evolution of surveying. In addition, a variety of technical manuals and field guides from the Army, War Department, and Department of Interior were used by surveyors. These were included in the exhibit as well (Figure 4).

Surveying is generally defined as the art of measuring the earth's surface using angles and distances (US Dept. of the Interior 1969, 4). There are three types of surveying: geodetic surveying determines shape and size of the earth; topographic surveying measures the features of the earth's surface including hills, valleys, rivers, and lakes as well as cultural features like buildings, railroads, and cemeteries; and cadastral surveying defines property boundaries for land ownership.
The types of tools used for these different classes of surveying are largely the same, even though they have changed as modern mapping technology has taken hold. When out in the field, surveyors usually affixed their tools to a tripod, as seen in many historical photographs. An assortment of surveying tools was displayed within the exhibit including an alidade, clinometer, planimeter, wagon wheel odometer, compass, and survey marker (Figure 5). The alidade consists of a telescope attached to a level plane and was a key tool used in topographic surveying. The telescope can determine vertical angles and therefore changes in elevation or land surface between points. In the field, the alidade would be mounted to a drafting table on a tripod set at an optimal height for topographers to create topographic maps in the field while surveying. The clinometer is a device used to measure vertical angles of slope and the planimeter is used to measure the area of a two-dimensional space on a map.

An adjacent exhibit case also contained larger historical surveying tools including a surveyor's chain, heliotrope, and transit (Figure 5). The surveyor's chain was an early measurement tool, 66 feet in length and made of iron to keep it functional despite being dragged across rough terrain. The rings comprising each link were made in such a way that the chain could never tangle when thrown.

The heliotrope was invented by the famed mathematician Friedrich Gauss in 1821 to measure longer distances. This instrument uses a small mirror to reflect sunlight 

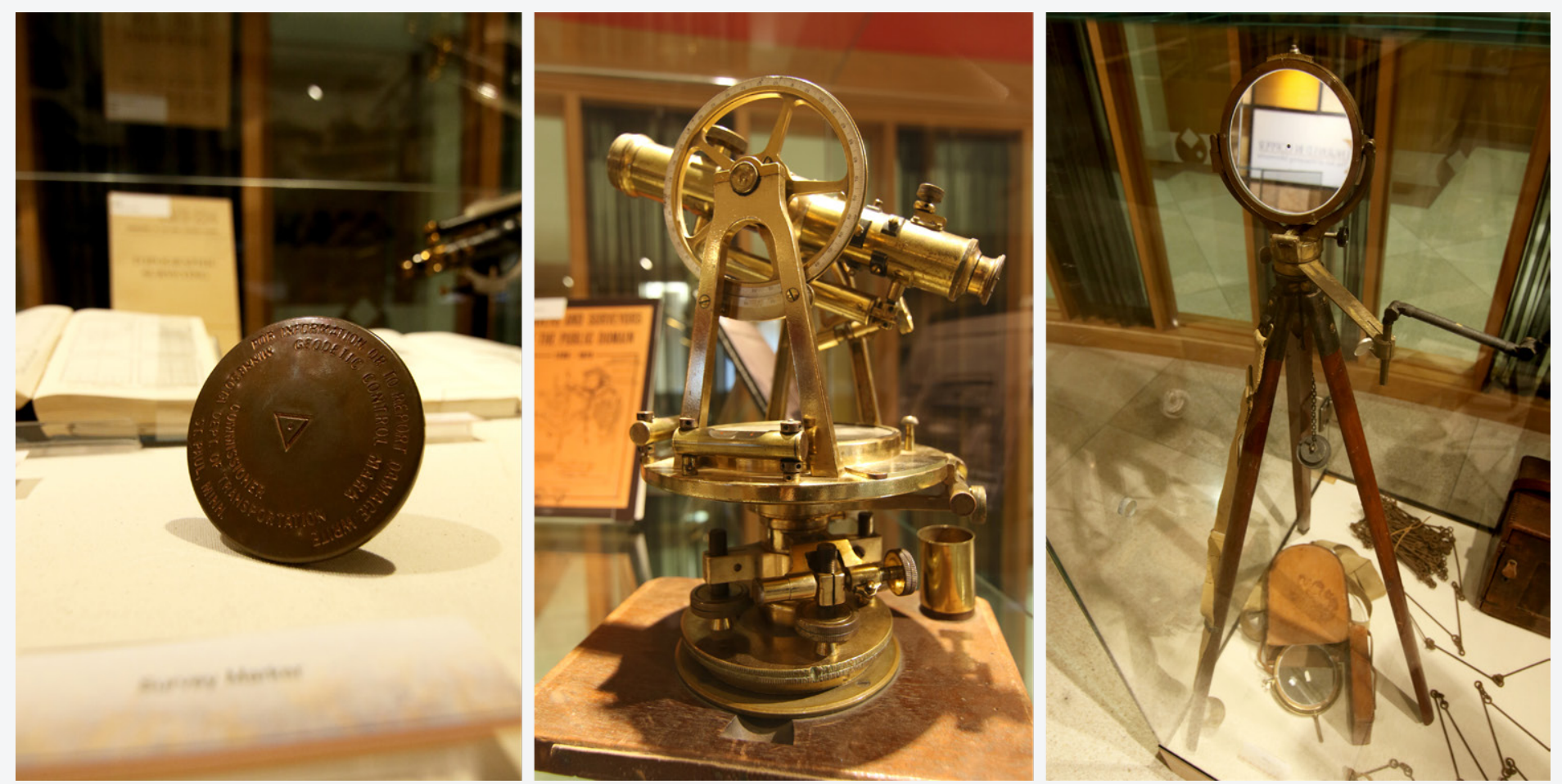

Figure 5. From left to right: survey marker, transit, and heliotrope.

to another surveyor or station and, through triangulation, measures the distance between the two points. Thus the name heliotrope, which is derived from the Greek words helios, meaning "the sun," and tropos, meaning "to turn." Consequently, the heliotrope could only be used on sunny days but its usefulness outweighed this drawback.

A surveyor used a transit to determine angles and measure straight distances. The transit comprised a telescope, a vernier scale (similar to a protractor), and a compass, and was used in conjunction with the heliotrope. A surveyor on the other side of the heliotrope would line up the transit with the heliotrope using the compass to make sure a straight line was made. Then the telescope was used to sight the mirror reflecting the light. The vernier scale is attached to the telescope, so that moving the telescope to find the mirror would give the surveyor the angle between the ground and the light, to a precision of minutes of an angle. Using these angles, surveyors could determine the distance between the two points.

After surveying was completed, various printing methods were used to create a map. The copper plates featured in this exhibit were used to print topographic maps with surveying data for the first half of the $20^{\text {th }}$ century.
Each copper plate was hand etched by a map engraver in the Map Division of the USGS. A transfer method was then used to reproduce the image from the copper plate onto a lithographic stone for mass production printing. This was necessary because the copper plate engraving would have degraded given the very large volume of maps printed by the USGS. Between the 1880s and the 1950s, more than 25,000,000 sheets were printed (Evans 2009, 149).

The mapmaking process was somewhat complicated. Drawings of field data from surveyors and topographers were prepared by drafting technicians. The drawings were then transferred to the copper plates. One early method was to coat the copper plate with a thin layer of wax and then use carbon paper to transfer the image (Phillips 1997, 13). A later method involved photographing the original drawing, using the glass negative to make a contact print on a zinc plate, transferring the image from the zinc plate to a celluloid sheet with graphite ink, and finally burnishing the image onto the wax layer on the copper plate (Phillips 1997, 14).

The exhibit also featured government documents related to mapmaking including items from the Topographic Instructions series published by the USGS (Figure 6). The 
series constitutes a comprehensive manual of topographic surveying and map production.

In addition to displaying the copper plates, we were able to work with the Art Department at the University of Minnesota to create new prints from the historic plates. In order to highlight the three separate colors used to print the original maps, they made new prints using a single color for each sheet (Figure 7).

The exhibit also touched on the evolution of government mapping. The Department of Defense (DoD) began using Global Positioning System (GPS) technology in the 1970s and today most government made maps are generated by the collection of geographic data via GIS databases (NASA 2012). Consequently, the USGS and DoD published a variety of government publications on the usage of geographic data in mapmaking as well as modern uses for cartographic information. Some of these government publications along with other monographs about GIS and its real-world applications were on display in the exhibit (Figure 8).

With the change in technology came a change in hardware and software formats. To help demonstrate this, an old computer keyboard and mouse set were placed in the exhibit next to a CD-ROM about using GIS to analyze topographic changes in Pennsylvania and other documents and monographs about GIS usage in various sectors (Figure 8).

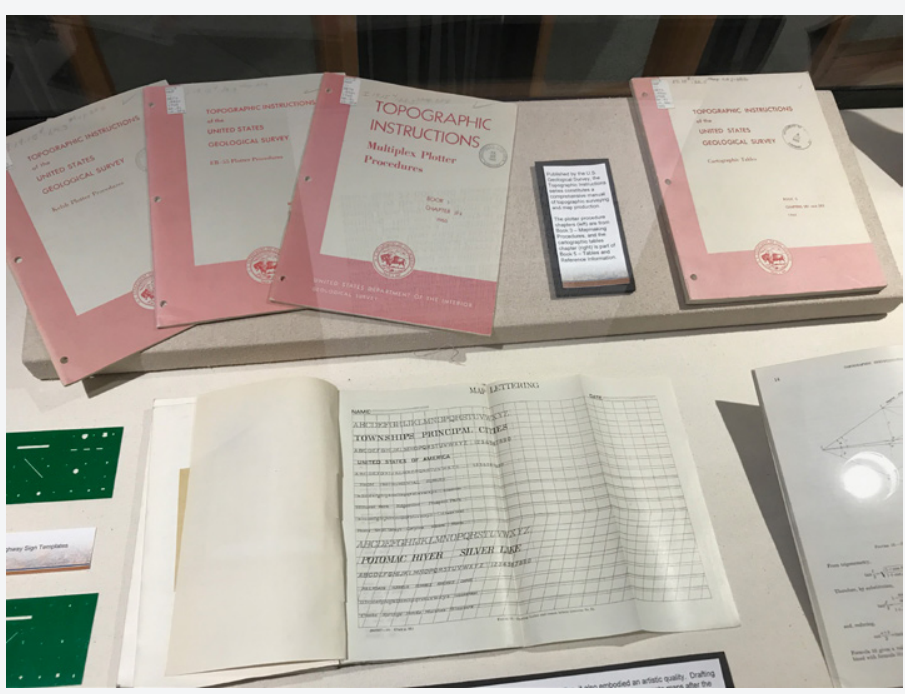

Figure 6. Government documents from the USGS Topographic Instructions series.

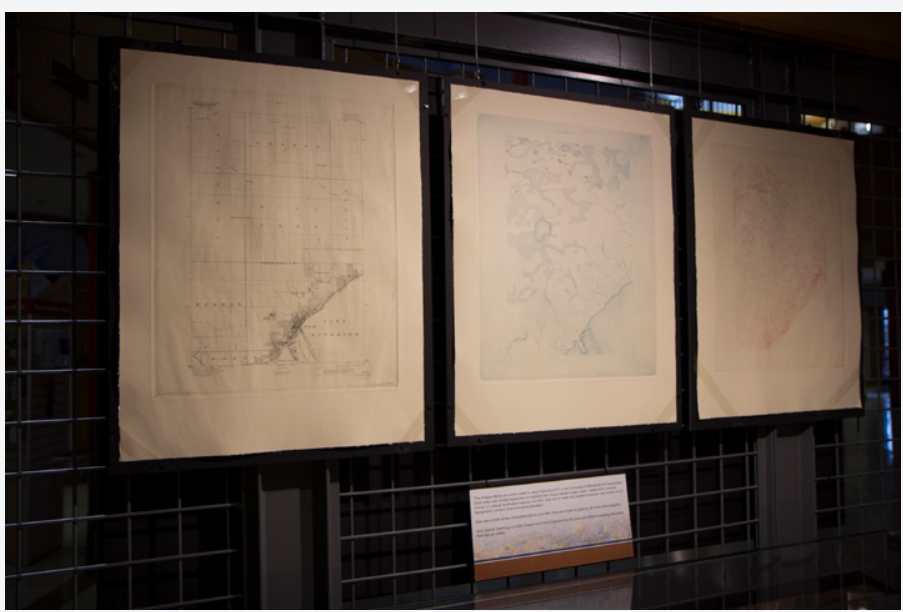

Figure 7. New prints from the historical copper plates.
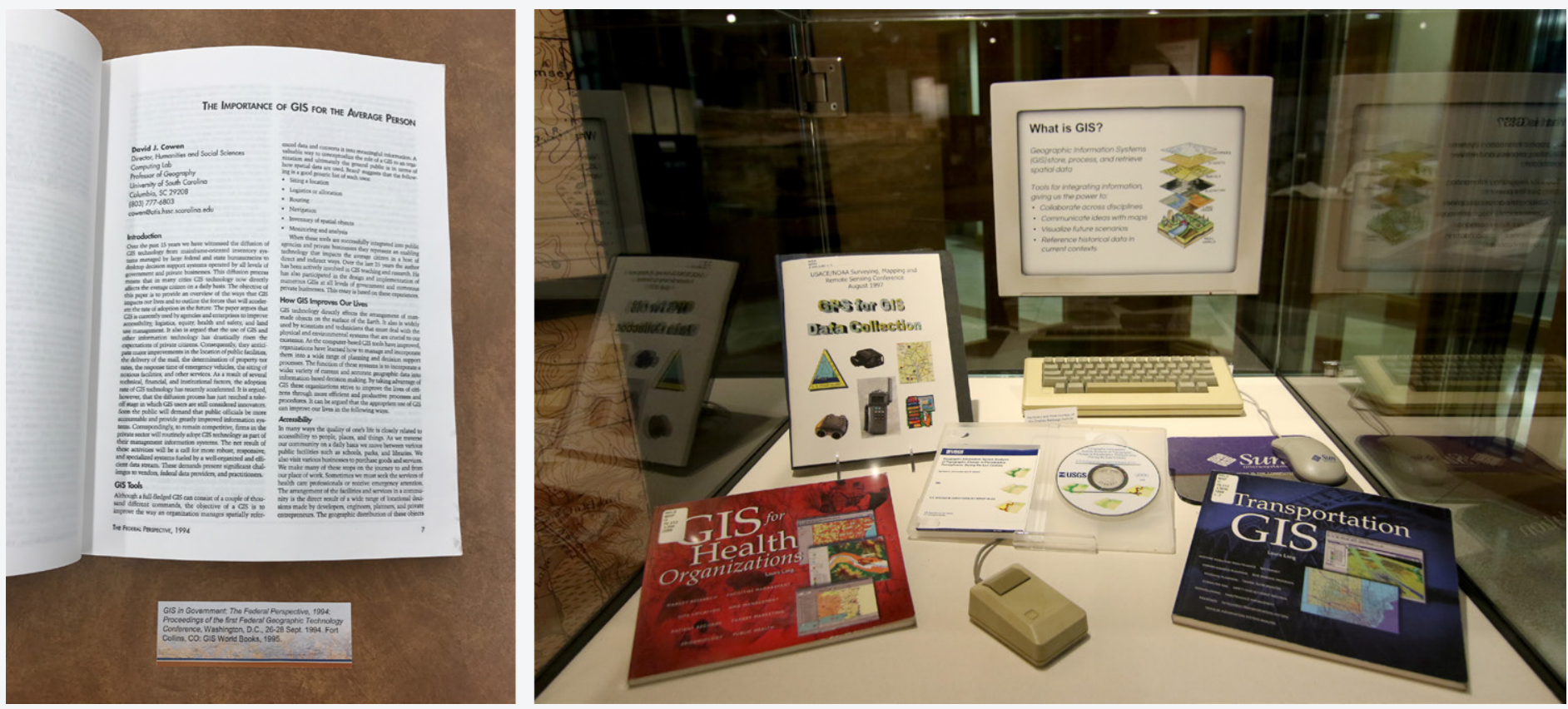

Figure 8. Left: "The Importance of GIS for the Average Person" from GIS in Government: The Federal Perspective, 1994. Right: interior of the GIS case. 
An exhibit opening was held on March 8, 2017 in the Elmer L. Andersen Library with approximately 140 attendees including alumni, map enthusiasts and experts, community members, faculty, students, and artists. There were two speakers at the event: Edie Overturf, Visiting Assistant Professor of Printmaking in the University of Minnesota's Art Department, and Ron Wencl, US Geological Survey National Map Liaison to Minnesota and Wisconsin.

Edie discussed the technical process of making prints with the copper plates, using photographs taken during the printing process to give the audience a visual representation of the steps involved in creating a print (Figure 9). The prints Edie and her graduate student made from the Duluth cultural, topographic, and hydrographic plates were showcased in the exhibit next to the plates from which the prints were pulled.

Ron spoke about the evolving mapping techniques and tools utilized by the USGS, the history of the Department of Interior and directors of the USGS, and how to access various types of maps online through different USGS portals and databases.

This exhibit was a great opportunity to highlight the richness of the map and government publications collections at the University of Minnesota, and to showcase the USGS copper plates that were a vital part of mapmaking history. Through this exhibit, attendees were able to learn about the complexity and artistry of mapmaking, the myriad tools necessary for the surveying and map production processes, and the plethora of uses for maps in a contemporary world.

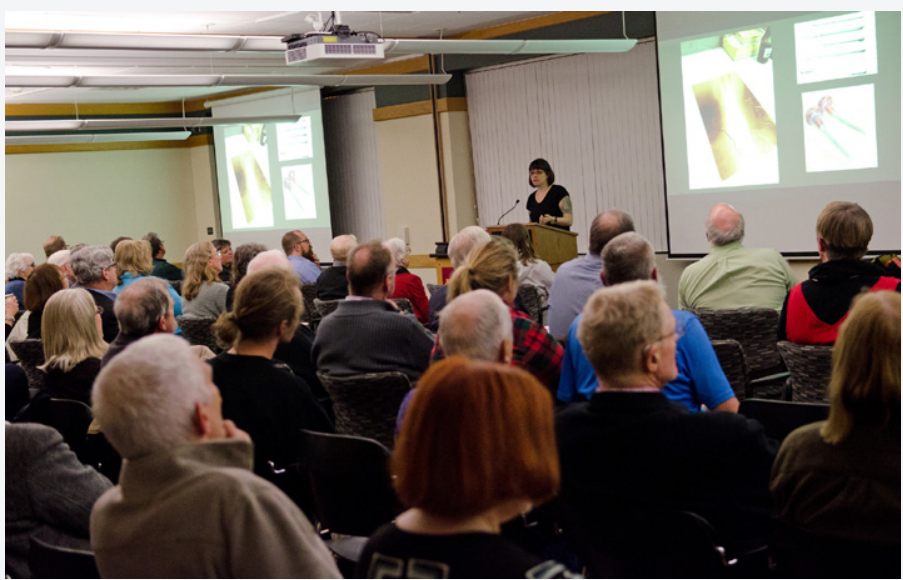

Flgure 9. Edie Overturf speaking at the event.

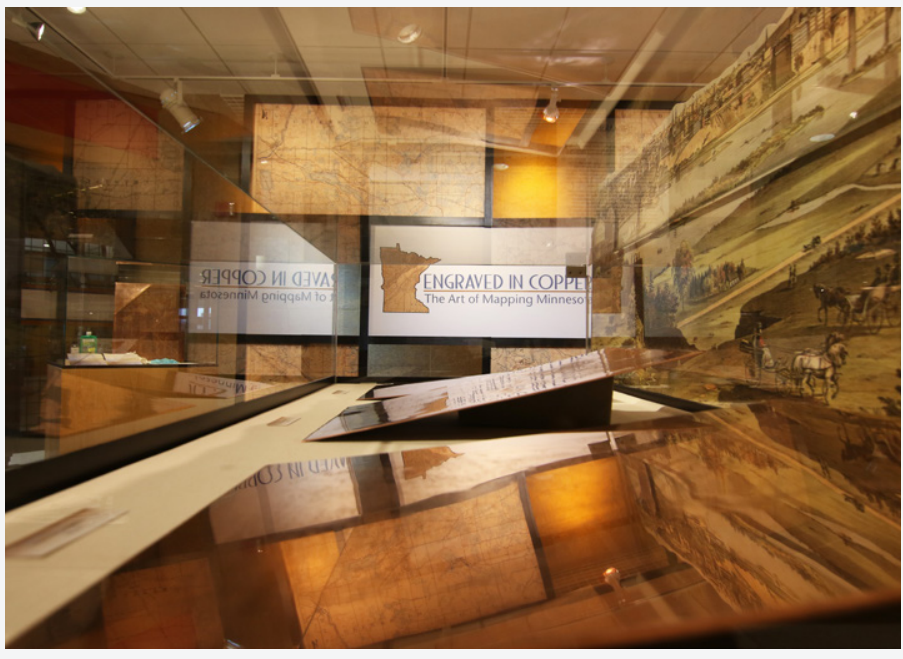

Figure 10. Close up of three copper plates.

\section{REFERENCES}

Evans, R. T., and H. M. Frye. 2009. History of the Topographic Branch (Division). Reston, VA: US Geological Survey.

NASA. 2012. "Global Positioning System History." Last modified July 30, 2015. https://www.nasa.gov/ directorates/heo/scan/communications/policy/GPS_ History.html.

Phillips, H. 1997. "Copperplate Engraving for the Production of Topographic Maps at the USGS." Meridian 11: 5-21.
US Department of the Interior, Bureau of Land Management. 1969. Surveying Our Public Lands. Washington, DC: Bureau of Land Management. 1988. Surveying Our Public Lands. Washington, DC: Bureau of Land Management.

USGS. 2015. "USGS Engravings Offered to the Public." Last modified March 30, 2015. https://www.usgs.gov/ news/usgs-engravings-offered-public. 